\title{
Spino-pelvic radiological parameters in normal Indian population
}

\author{
Roop Singh ${ }^{1, *}$, Sushil Kumar Yadav ${ }^{1}$, Sushma Sood ${ }^{2}$, Rohtas Kumar Yadav ${ }^{3}$, and Ravi Rohilla ${ }^{4}$ \\ 1 Department of Orthopaedic Surgery, Paraplegia \& Rehabilitation, Pt. B.D. Sharma PGIMS, Rohtak 124001, Haryana, India \\ 2 Department of Physiology, Pt. B.D. Sharma PGIMS, Rohtak 124001, Haryana, India \\ 3 Department of Radiodiagnosis, Pt. B.D. Sharma PGIMS, Rohtak 124001, Haryana, India \\ 4 Department of Social and Preventive Medicine, Pt. B.D. Sharma PGIMS, Rohtak 124001, Haryana, India
}

Received 25 August 2015, Accepted 15 January 2016, Published online 30 April 2018

\begin{abstract}
Introduction: There is increasing emphasis on the sagittal spino-pelvic alignment and its interpretation is of critical importance in the management of spinal disorders. A cross-sectional study of several spino-pelvic radiographic parameters was conducted to determine the physiological values of these parameters, to calculate the variations of these parameters according to epidemiological data, and to study the relationships among these parameters. Material and method: Fifty normal healthy volunteers (29 males and 21 females) with no history of back pain were selected and were subjected to standing sagittal spino-pelvic radiographs. All the measurements of various radiographic parameters were performed with use of a software program. A statistical analysis was done to study the relationships among them.

Results: The mean values of pelvic incidence (PI) and lumbar Lordosis Angle (LLA) were $48.52 \pm 8.99$ and $58.78 \pm 9.51$, respectively. There was statistical difference between male and female parameters in LLA, lumbosacral angle (LSA), sacral horizontal angle (SHA), sacral inclination angle (SIA), sacropelvic angle (PRS1), pelvisacral angle (PSA), and PI. A majority of parameters had higher values for female subjects when compared to male subjects. PI was positively correlated with LLA, pelvic angle (PA), pelvic overhang (PO), pelvic tilt (PT), sacrofemoral distance (SFD), SHA, and sacropelvic translation (SPT), which were highly significant, whereas LLA was positively correlated with SHA and SIA only. PI and LLA were both negatively correlated with PSA, pelvic thickness (PTH), and PRS1.

Conclusions: This study presents the various spino-pelvic radiographic parameter values of a sample of the normal asymptomatic Indian population. There was significant difference in radiographic parameters between males and females in about half of the parameters studied in the sample. The values obtained are comparable with the values presented as normal in the literature. A comparison of the study results with data published about other populations revealed no differences in any of the pelvic parameters between the Indian, Brazilian, and Korean populations.
\end{abstract}

Key words: Spino-pelvic alignment, Radiologic parameters, Pelvic incidence, Lumbar lordosis angle.

\section{Introduction}

The sagittal spino-pelvic alignment pattern varies from one individual to another and is specific to each person. The vertebral column plays an important role in the support and locomotion of the human body. An understanding of the elements that compose it is essential for learning about its role in body balance and alignment. Many investigators have reported the importance of the sagittal plane contour in the normal function of the spine and in various diseased states [1, 2].

To analyze the consequences of changes in sagittal balance in each individual, we need to understand the normal

\footnotetext{
*Corresponding author: drroopsingh@rediffmail.com
}

parameters for the population. The judgment of normality can be made possible by analyzing the normal patterns of sagittal curvature and characteristics of each pattern of sagittal curvatures. If sagittal alignment is abnormal, more expenditure of energy and high demand on the dynamic and static stabilizer are required to compensate the abnormal sagittal alignment for balance $[3,4]$.

Several studies have evaluated the relationship between the position of the pelvis and spinal alignment [4-16]. However, it is important to know the values of these radiographic parameters in healthy individuals, without spinal disease. Although some studies address these parameters, it is interesting to evaluate them in a specific population as there are structural 


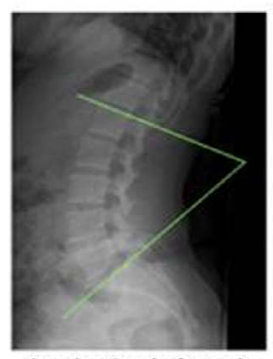

Lumbar Lordosis Angle

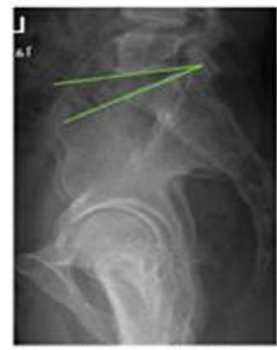

Lumbosacral Angle

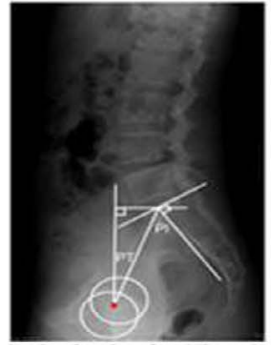

Red point showing Hip Axis

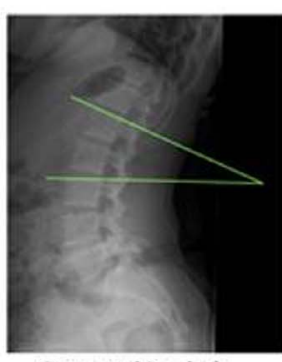

Segmental Lordosis
Angle $\mathrm{L} 1-\mathrm{L} 3$

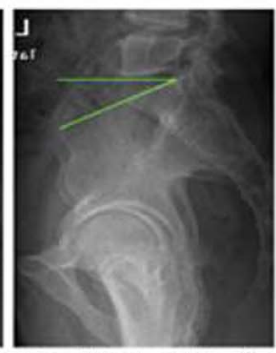

Sacral Horizontal Angle

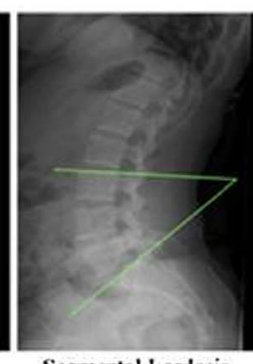

Segmental Lordosi Angle 1.3-S

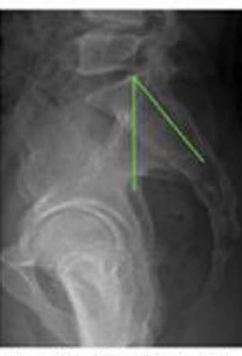

Sacral Inclination Angle

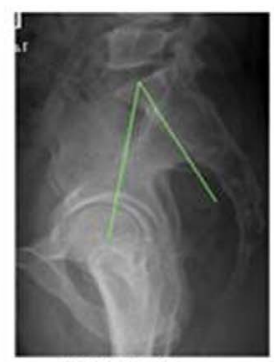

Pelvic Incidence

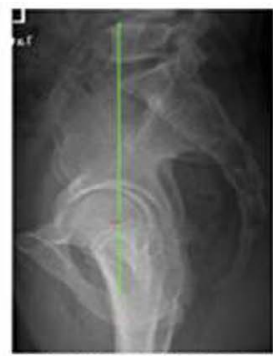

Sacrofemoral Distance

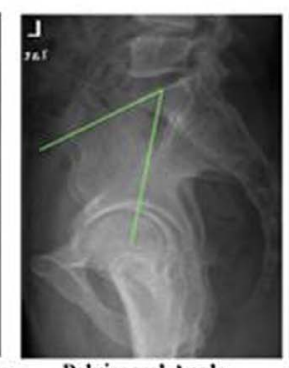

Pelvisacral Angle

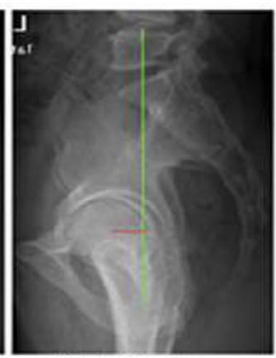

Pelvic Overhang

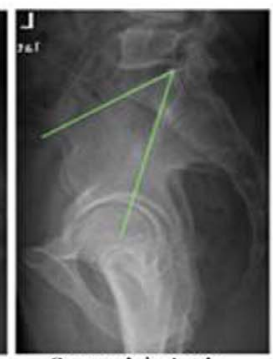

Sacropelvic Angle

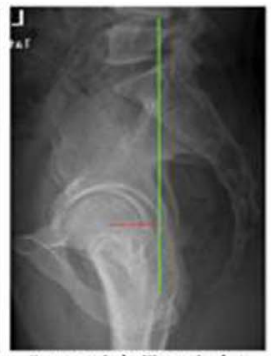

Sacropelvic Translation

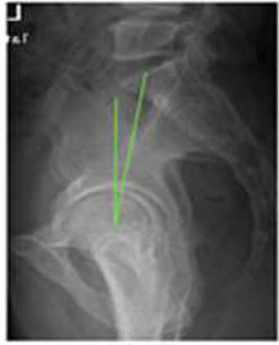

Pelvic Tilt

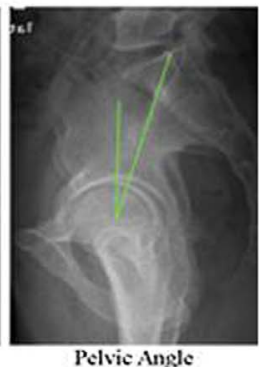

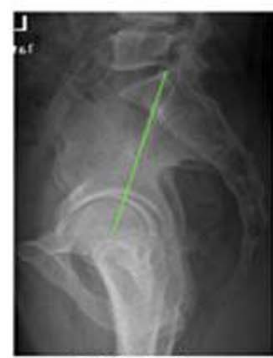

Pelvic Radius

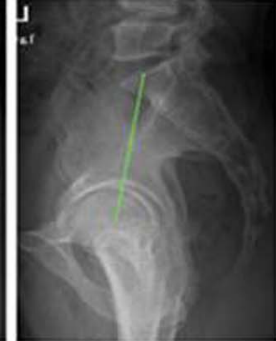

Pelvie Thickness

Figure 1. Shows schematic representation of various spino-pelvic parameter measurements on the radiographs.

differences between different population groups. Various studies have been conducted with evaluations of individuals from the European, Causcasian, Brazilian, and Korean populations $[1-3,10-12,17]$. However, a similar study has not yet been conducted for the Indian population.

The objective of this study is to observe the parameters of sagittal and spino-pelvic balance in a sample of the Indian population consisting of volunteer asymptomatic individuals, in order to establish the relationship between these parameters, age, and sex and to compare the results with those of other studies that cover other population groups.

\section{Materials and methods}

The present study was conducted from May 2012 to November 2014 in a tertiary care center. Fifty subjects agreed to participate in the study. All were volunteers and met the following inclusion criteria: an age between 18 and 50 years, no history of a spinal disorder or spinal surgery, and no radiographic abnormality detected prior to or during the study. Hip, knee, and ankle abnormalities were ruled out by clinical examination. All volunteers provided informed consent. The study population consisted of 50 volunteers (29 men and
21 women), with a mean age of $31.14 \pm 9.62$ years. The epidemiological and morphological characteristics of this cohort were obtained from the following data: age, gender, weight, and height. The body mass index was calculated as the weight in kilograms divided by the square of the height in meters.

Informed written consent was obtained from all the subjects participating in the study. The institutional review board cleared the study and ethical clearance was taken.

Each volunteer was thoroughly examined clinically to rule out any obvious spinal pathology and was subjected to sagittal spino-pelvic radiographs.

\section{Sagittal spino-pelvic radiographs}

Lateral radiographs of the lumbo-pelvic region were taken using Philips digital radiography system. The participants were instructed to stand straight and relaxed, with their knees fully extended. The elbows were flexed, with both hands resting on a horizontal bar at the level of their shoulders. The filmto-focus distance was $2 \mathrm{~m}$.

The following angles (Figure 1) were measured on the sagittal spino-pelvic radiographs using open source software 
OsiriX (version 3.8.1, Pixmeo, Geneva, Switzerland) downloaded from http://www.osirix-viewer.com/.

(a) Lumbar Lordosis Angle (LLA) - The angle between the cephalad endplate of the first lumbar vertebra and the cephalad endplate of sacrum.

(b) Segmental Lordosis Angle (SLA) L1-L3 - The angle between the cephalad endplate of the first lumbar vertebra and the cephalad endplate of third lumbar vertebra.

(c) SLA L3-S1 - The angle between the cephalad endplate of the third lumbar vertebra and the cephalad endplate of sacrum.

(d) Lumbo-sacral angle (LSA) - The angle between the line along the upper border of sacrum and lower border of L5 vertebra.

(e) Sacral Horizontal Angle (SHA) - The angle between a horizontal line and a line drawn tangentially to the upper surface of sacrum.

(f) Sacral Inclination Angle (SIA) - The angle between the line along the posterior border of S1 body and the reference vertical line.

(g) Pelvic tilt (PT) - The angle between the line joining the hip axis (midpoint of bicoxofemoral axis) and the center of the S1 endplate and the reference vertical line.

(h) Pelvic angle (PA) - The angle between the line joining the hip axis and the posterior corner of the S1 endplate and the reference vertical line.

(i) Pelvic incidence (PI) - The angle between the line joining the hip axis and the center of S1 endplate and the line orthogonal to the $\mathrm{S} 1$ endplate.

(j) Pelvisacral Angle (PSA) - The angle between the line joining the hip axis and the center of S1 endplate and the line along the S1 endplate.

(k) Sacropelvic angle (PRS1) - The angle between the line joining the hip axis and the posterior corner of the S1 endplate and the line along the S1 endplate.

(1) Sacrofemoral distance (SFD) - The horizontal distance between the reference vertical line through the hip axis and the reference vertical line through the anterior corner of the S1 endplate.

(m) Pelvic overhang (PO) - The horizontal distance between the reference vertical line through the hip axis and the reference vertical line through the center of the S1 endplate.

(n) Sacropelvic translation (SPT) - The horizontal distance between the reference vertical line through the hip axis and the reference vertical line through the posterior corner of the S1 endplate.

(o) Pelvic Radius (PR) - The distance of the line joining the hip axis and the posterior corner of the S1 endplate.

(p) Pelvic thickness (PTH) - The distance of the line joining the hip axis and the center of $\mathrm{S} 1$ endplate.

(q) Lordosis Tilt Angle (LTA) - The angle between the anterior superior edge of $\mathrm{S} 1$ and the anterior superior edge of L1 with the reference vertical line is defined as the lordosis tilt angle. By convention, this angle is expressed as a negative value if the limit of the lumbar lordosis is posterior to the anterior aspect of $\mathrm{S} 1$, and positive if it is anterior to $\mathrm{S} 1$.
Table 1. Demographic data study population.

\begin{tabular}{lc}
\hline & Mean $\pm S D, n=50$ \\
\hline Age (years) & $31.14 \pm 9.62$ \\
Sex & \\
Male & 29 \\
Female & 21 \\
Height $(\mathrm{m})$ & $1.64 \pm 0.064$ \\
Weight $(\mathrm{kg})$ & $66.34 \pm 5.33$ \\
BMI $\left(\mathrm{kg} / \mathrm{m}^{2}\right)$ & $24.72 \pm 2.36$ \\
\hline
\end{tabular}

Table 2. Findings on sagittal spino-pelvic radiographs among study group.

\begin{tabular}{lc}
\hline Radiographic parameter & $\begin{array}{c}\text { Mean } \pm S D \text { (range) } \\
n=50\end{array}$ \\
\hline Lumbar Lordosis Angle (LLA) $\left(^{\circ}\right)$ & $58.78 \pm 9.51(37$ to 79$)$ \\
Lumbo-sacral angle (LSA) $\left({ }^{\circ}\right)$ & $10.56 \pm 3.58(5$ to 20$)$ \\
Pelvic angle (PA) $\left({ }^{\circ}\right)$ & $13.86 \pm 6.76(2$ to 39$)$ \\
Pelvic incidence (PI) $\left({ }^{\circ}\right)$ & $48.52 \pm 8.99(33$ to 69$)$ \\
Pelvic overhang (PO) (mm) & $18.22 \pm 12.78(-9$ to 61$)$ \\
Pelvic radius (PR) (mm) & $128.90 \pm 8.86(111$ to 157$)$ \\
Pelvisacral Angle (PSA) $\left({ }^{\circ}\right)$ & $41.36 \pm 9.11(21$ to 57$)$ \\
Pelvic tilt $(\mathrm{PT})\left({ }^{\circ}\right)$ & $9.30 \pm 7.16(-5$ to 37$)$ \\
Pelvic thickness (PTH) (mm) & $116.94 \pm 9.41(99$ to 147$)$ \\
Sacrofemoral distance (SFD) (mm) & $4.52 \pm 12.51(-23$ to 44$)$ \\
Sacral Horizontal Angle (SHA) $\left({ }^{\circ}\right)$ & $39.14 \pm 7.05(22$ to 55$)$ \\
Sacral Inclination Angle (SIA) $\left({ }^{\circ}\right)$ & $48.62 \pm 6.62(35$ to 62$)$ \\
Segmental Lordosis Angle (SLA) L1-L3 $\left({ }^{\circ}\right)$ & $17.54 \pm 3.81(9$ to 25$)$ \\
Segmental Lordosis Angle (SLA) L3-S1 $\left({ }^{\circ}\right)$ & $43.46 \pm 8.15(28$ to 64$)$ \\
Sacropelvic angle (PRS1) $\left({ }^{\circ}\right)$ & $37.02 \pm 8.05(18$ to 52$)$ \\
Sacropelvic translation $(\mathrm{SPT})(\mathrm{mm})$ & $30.82 \pm 13.82(4$ to 75$)$ \\
Lordosis Tilt Angle (LTA) $\left({ }^{\circ}\right)$ & $-2.48 \pm 4.98(-16$ to 10$)$ \\
\hline
\end{tabular}

\section{Statistical analysis}

Collected data were entered in the MS Excel spreadsheet, coded appropriately, and later cleaned for any possible errors in SPSS (Statistical Package for Social Studies) for Windows version 20. Categorical data were presented as percentage (\%). Normally distributed data were presented as means and standard deviation, or $95 \%$ confidence intervals (CIs). For comparing two groups containing quantitative variables, independent sample $t$-test was used. In case of violation of normality, Mann-Whitney test was used. Pearson's correlation was used for measuring correlation coefficient between two quantitative variables. In case of qualitative variables, Spearman's correlation coefficient was applied. All tests were performed at a 5\% level significance, thus a difference was significant if the value was less than 0.05 $(p$ value $<0.05)$

\section{Results}

Table 1 shows the demographic data of study population. Of the 50 volunteers analyzed, 29 were males and 21 were females with a mean body mass index (BMI) of $24.72 \pm 2.36 \mathrm{~kg} / \mathrm{m}^{2}$.

Table 2 shows values of various radiological parameters of the study group. The mean values of PI and LLA were $48.52 \pm 8.99$ and $58.78 \pm 9.51$, respectively. 
Table 3. Pelvic and spinal parameters according to sex.

\begin{tabular}{|c|c|c|c|c|c|}
\hline Parameter & Gender & $N$ & Mean & $S D$ & $p$ value \\
\hline \multirow[t]{2}{*}{ Height } & $\mathrm{M}$ & 29 & 1.6866 & .03618 & .001 \\
\hline & $\mathrm{F}$ & 21 & 1.5762 & .02889 & \\
\hline \multirow[t]{2}{*}{ Weight } & $\mathrm{M}$ & 29 & 67.9655 & 4.30517 & .010 \\
\hline & $\mathrm{F}$ & 21 & 64.0952 & 5.88986 & \\
\hline \multirow[t]{2}{*}{ BMI } & M & 29 & 23.9041 & 1.50582 & .008 \\
\hline & $\mathrm{F}$ & 21 & 25.8562 & 2.86638 & \\
\hline \multirow[t]{2}{*}{ LLA } & $\mathrm{M}$ & 29 & 56.2069 & 9.54081 & .023 \\
\hline & $\mathrm{F}$ & 21 & 62.3333 & 8.46955 & \\
\hline \multirow[t]{2}{*}{ SLA1 } & M & 29 & 17.0000 & 4.01782 & .243 \\
\hline & $\mathrm{F}$ & 21 & 18.2857 & 3.46616 & \\
\hline \multirow[t]{2}{*}{ SLA2 } & M & 29 & 41.4828 & 6.40659 & .059 \\
\hline & $\mathrm{F}$ & 21 & 46.1905 & 9.59489 & \\
\hline \multirow[t]{2}{*}{ LSA } & M & 29 & 9.3793 & 1.98950 & .005 \\
\hline & $\mathrm{F}$ & 21 & 12.1905 & 4.58933 & \\
\hline \multirow[t]{2}{*}{ SHA } & $\mathrm{M}$ & 29 & 37.0000 & 6.26783 & .010 \\
\hline & $\mathrm{F}$ & 21 & 42.0952 & 7.16174 & \\
\hline \multirow[t]{2}{*}{ SIA } & M & 29 & 46.7241 & 4.97060 & .026 \\
\hline & $\mathrm{F}$ & 21 & 51.2381 & 7.78399 & \\
\hline \multirow[t]{2}{*}{ PT } & $\mathrm{M}$ & 29 & 9.1724 & 8.40097 & .884 \\
\hline & $\mathrm{F}$ & 21 & 9.4762 & 5.19249 & \\
\hline \multirow[t]{2}{*}{ PA } & M & 29 & 13.8621 & 7.81813 & .998 \\
\hline & $\mathrm{F}$ & 21 & 13.8571 & 5.14087 & \\
\hline \multirow[t]{2}{*}{ PRS1 } & M & 29 & 38.9310 & 8.61449 & .047 \\
\hline & $\mathrm{F}$ & 21 & 34.3810 & 6.50750 & \\
\hline \multirow[t]{2}{*}{ PSA } & M & 29 & 43.7241 & 9.32698 & .030 \\
\hline & $\mathrm{F}$ & 21 & 38.0952 & 7.91773 & \\
\hline \multirow[t]{2}{*}{ PI } & M & 29 & 46.3103 & 9.28556 & .040 \\
\hline & $\mathrm{F}$ & 21 & 51.5714 & 7.79469 & \\
\hline \multirow[t]{2}{*}{ SPT } & M & 29 & 31.4828 & 16.00362 & .695 \\
\hline & $\mathrm{F}$ & 21 & 29.9048 & 10.39666 & \\
\hline \multirow[t]{2}{*}{ PO } & $\mathrm{M}$ & 29 & 17.8276 & 14.85422 & .802 \\
\hline & $\mathrm{F}$ & 21 & 18.7619 & 9.55460 & \\
\hline \multirow[t]{2}{*}{ SFD } & M & 29 & 3.4828 & 14.48058 & .497 \\
\hline & $\mathrm{F}$ & 21 & 5.9524 & 9.29234 & \\
\hline \multirow[t]{2}{*}{ PR } & M & 29 & 130.6207 & 8.75220 & .107 \\
\hline & $\mathrm{F}$ & 21 & 126.5238 & 8.65805 & \\
\hline \multirow[t]{2}{*}{ PTH } & M & 29 & 119.0345 & 9.74856 & .064 \\
\hline & $\mathrm{F}$ & 21 & 114.0476 & 8.30347 & \\
\hline \multirow[t]{2}{*}{ LTA } & M & 29 & -2.97 & 4.64 & 0.424 \\
\hline & $\mathrm{F}$ & 21 & -1.81 & 5.45 & \\
\hline
\end{tabular}

Table 3 shows the statistical comparison of various radiographic parameters according to gender. There was statistical difference between male and female parameters in LLA, LSA, SHA, SIA, PRS1, PSA, and PI. A majority of parameters had higher values for female subjects when compared to male subjects.

Table 4 shows Correlation of Pelvic Incidence and Lumbar Lordosis Angle with other radiographic parameters, age, gender, and BMI. PI was positively correlated with LLA, PA, PO, PT, SFD, SHA, and SPT, which were highly significant, whereas LLA was positively correlated with SHA and SIA only. PI and LLA were both negatively correlated with PSA, PTH, and PRS1.

Table 5 shows variations in radiographic parametersin overall and in males and females in different populations. The parameters among European population were comparatively higher than other studied populations.

Table 6 summarizes the findings of the studies done so far and the findings of the present study.

\section{Discussion}

The current study yields a physiological standard for several angular pelvic and spinal parameters that describe spinal balance, measured in a cohort of 50 asymptomatic adult volunteers of Indian resident population.

In the past three decades, increasing emphasis is being placed on quantitative evaluation of the parameters of sagittal spino-pelvic alignment as it is useful for clinical application and treatment of spino-pelvic pathologies. The harmony among spino-pelvic parameters is therefore of significant importance [4-19]. However, for us to correctly understand the effects of the loss of sagittal balance on the quality of life of each individual, we must know the normal values of the parameters used to evaluate sagittal and spinopelvic balance in the population.

A statistically significant difference was found between PI and gender in the present study with higher values of PI in 
Table 4. Correlation of pelvic incidence and lumbar lordosis angle with other radiographic parameters, age, gender, and BMI.

\begin{tabular}{lrcr}
\hline $\begin{array}{l}\text { Correlation } \\
\text { of PI with }\end{array}$ & $\begin{array}{c}r \text { value } \\
(p \text { value })\end{array}$ & $\begin{array}{c}\text { Correlation of } \\
\text { LLA with }\end{array}$ & $\begin{array}{c}r \text { value } \\
(p \text { value })\end{array}$ \\
\cline { 2 - 2 } & Study group & & Study group \\
\hline LLA & $0.543(0.000)$ & PI & $0.543(0.000)$ \\
LSA & $-0.168(0.245)$ & LSA & $0.111(0.443)$ \\
PA & $0.574(0.000)$ & PA & $-0.188(0.185)$ \\
PO & $0.614(0.000)$ & PO & $-0.157(0.267)$ \\
TR & $-0.456(0.000)$ & TR & $-0.166(0.247)$ \\
PSA & $-0.993(0.000)$ & PSA & $-0.558(0.000)$ \\
PT & $0.642(0.000)$ & PT & $-0.127(0.367)$ \\
PTH & $-0.574(0.000)$ & PTH & $-0.345(0.015)$ \\
SFD & $0.684(0.000)$ & SFD & $-0.019(0.864)$ \\
SHA & $0.630(0.000)$ & SHA & $0.821(0.000)$ \\
SIA & $0.403(0.004)$ & SIA & $0.570(0.000)$ \\
PRS1 & $-0.978(0.000)$ & PRS1 & $-0.588(0.000)$ \\
SPT & $0.527(0.000)$ & SPT & $-0.219(0.122)$ \\
LTA & $0.465(0.001)$ & LTA & $0.216(0.132)$ \\
Age & $0.364(0.009)$ & Age & $0.013(0.926)$ \\
BMI & $0.301(0.034)$ & BMI & $0.357(0.011)$ \\
Gender & $-0.290(0.041)$ & Gender & $-0.293(0.039)$ \\
\hline
\end{tabular}

females. Vialle et al. reported similar results with statistically significant differences between genders $(p<0.05)$, with higher PI values for females [1]. However, a number of studies reported no relationship between PI and gender [7, 8, 14, 15].

A positive correlation was found between PI and age in the study group $(r=0.36 ; p<0.01)$ while Vialle et al. reported no relationship in normal adults [1]. A significant positive correlation was found between PI and BMI in the study group $(r=0.30, p=0.03)$. Boulay et al. found similar significant correlation of $r=0.41(p=0.005)$ in normal adults [13].

A number of studies evaluated the relationship between PI and LLA, reporting significant correlation of $r=0.40-0.74$ $(p<0.001)[8,12,14,19]$. In the present study, we found a significant positive correlation in the study group $(r=0.54)$ with $p<0.001$.

Itoi reported a correlation of $r=-0.211 \quad(p=0.035)$ between PSA and LLA [10]. Similar significant negative correlation was present in our study with $r=-0.56$ $(p<0.001)$. High correlation was reported between PI and sacropelvic angle (PRS1) with $r=-0.95(p<0.001)$ [14]. In the present study, significant negative correlation was found between PI and PRS1 with $r=-0.98(p<0.001)$.

Jackson et al. found significant negative correlation $(r=-0.80$ to $-0.62, p<0.001)$ between PRS1 and LLA $[6,18]$. In the present study, we also found significant negative correlation with $r=-0.59 \quad(p<0.001)$. Legaye reported significant positive correlation between PRS1 and PR $(r=0.38-0.73 ; p<0.001)$ [14]. In the present study, we also found significant correlation between these two spino-pelvic parameters $(r=0.46 ; p=0.001)$.

In the present study, a significant correlation was found between LLA and other spino-pelvic parameters i.e. SHA $(r=0.82 ; p<0.001)$ and SIA $(r=0.57 ; p<0.001)$. There was no significant correlation regarding SFD, PO, and SPT. Similar significant correlation was found between PI and other spinopelvic parameters i.e. PA $(r=0.57)$, SFD $(r=0.68)$, PO $(r=0.61)$, and SPT $(r=0.53)$.

The mean values of PI $(48.52 \pm 8.99, n=50)$ in the present study in the control group were found similar to the data reported in the literature for Korean $(47.8 \pm 9.5, n=86)$ and Brazilian (48.7 $\pm 9.6, n=50)$ populations and somewhat different from data of European population $(54.7 \pm 10.6$, $n=300)$ [1-3].

India is a country of mixed population. This study presents the results of an analysis of a small sample of healthy individuals. It can be noticed that the values obtained from the sample are within the values described as normal in the literature. In our study, there were differences in the radiographic parameters (LLA, LSA, SHA, SIA, PRS1, PSA and PI) when compared by sex of the individuals evaluated. A majority of parameters had higher values for female when compared to male subjects. When we compare the average values and standard deviations obtained in this study with those published in the literature for European, Brazilian, and Korean populations, we can see that there were no differences for any of the pelvic parameters between the Indian, Brazilian, and Korean populations, even when compared by sex. The values of pelvic incidence of the European population were higher than those of the Indian population sample. Both for the total sample and in the comparison by sex, the values of sacral slope of the European population were higher than those of the Indian population sample. Both for the total population and for the female group, the pelvic tilt values of the European population were similar to those obtained for the sample population studied. These data show

Table 5. Comparison of different populations.

\begin{tabular}{|c|c|c|c|c|c|c|c|c|c|}
\hline & \multirow[t]{2}{*}{ Population } & \multicolumn{2}{|c|}{$\begin{array}{c}\text { Brazilian [3] } \\
(n=50)\end{array}$} & \multicolumn{2}{|c|}{$\begin{array}{l}\text { European [1] } \\
\quad(n=300)\end{array}$} & \multicolumn{2}{|c|}{$\begin{array}{l}\text { Korean [2] } \\
(n=86)\end{array}$} & \multicolumn{2}{|c|}{$\begin{array}{l}\text { Indian } \\
(n=50)\end{array}$} \\
\hline & & Mean & $S D$ & Mean & $S D$ & Mean & $S D$ & Mean & $S D$ \\
\hline \multirow[t]{3}{*}{$\overline{\mathrm{PI}}$} & Total & 48.7 & 9.6 & 54.7 & 10.6 & 47.8 & 9.5 & 48.5 & 9.0 \\
\hline & Male & 49.1 & 6.4 & 53 & 10.6 & 48.8 & 7.3 & 46.31 & 9.28 \\
\hline & Female & 48.3 & 9.6 & 56 & 10 & 46.1 & 9.5 & 51.57 & 7.79 \\
\hline \multirow[t]{3}{*}{ SS } & Total & 38 & 8.4 & 41.2 & 8.5 & 36.3 & 8.6 & 39.1 & 7.0 \\
\hline & Male & 38.2 & 6.9 & 41 & 8.5 & 37.3 & 7.1 & 37.00 & 6.26 \\
\hline & Female & 37.8 & 8.4 & 43.2 & 8.4 & 34.4 & 8.6 & 42.09 & 7.16 \\
\hline \multirow[t]{3}{*}{ PT } & Total & 12.15 & 6.2 & 13.2 & 6 & 11.5 & 5.4 & 9.3 & 7.2 \\
\hline & Male & 12.1 & 6.2 & 13 & 6 & 11.4 & 5.4 & 9.17 & 8.40 \\
\hline & Female & 12.2 & 5.3 & 13.6 & 6 & 11.6 & 5.1 & 9.47 & 5.19 \\
\hline
\end{tabular}


Table 6. Existing studies and reported values.

\begin{tabular}{|c|c|c|c|c|}
\hline$\underline{\text { Study }}$ & $N$ & Age (years) & PR (mm) & Description \\
\hline Jackson et al. (1998) [5] & 50 & $39.4 \pm 9.5$ & $135 \pm 8.6$ & Normal \\
\hline Jackson et al. (2003) [6] & 75 & 39 & $136.8 \pm 8.9$ & Normal \\
\hline \multirow[t]{3}{*}{ Present study } & 50 & $31.14 \pm 9.62$ & $128.9 \pm 8.86$ & Normal \\
\hline & 29 & & $130.62 \pm 8.75$ & Normal males \\
\hline & 21 & & $126.52 \pm 8.65$ & Normal females \\
\hline Study & $N$ & Age (years) & PTH (mm) & Description \\
\hline Duval-Beaupere et al. (1992) [7] & 17 & $29.4 \pm 11.0$ & $120 \pm 7.5$ & Normal \\
\hline \multirow[t]{2}{*}{ Rajnics et al. (2001) [8] } & 25 & $35.1 \pm 3.0$ & $155.5 \pm 19.3$ & Normal females \\
\hline & 15 & $33.5 \pm 2.9$ & $133.1 \pm 15.3$ & Normal males \\
\hline \multirow[t]{3}{*}{ Present study } & 50 & $31.14 \pm 9.62$ & $116.94 \pm 9.41$ & Normal \\
\hline & 29 & & $119.03 \pm 9.74$ & Normal males \\
\hline & 21 & & $114.04 \pm 8.30$ & Normal females \\
\hline Study & $N$ & Age (years) & $\operatorname{PSA}\left({ }^{\circ}\right)$ & Description \\
\hline During et al. (1985) [9] & 52 & & $41.3 \pm 10.0$ & Normal \\
\hline Itio $(1991)$ [10] & 18 & 72 & $33.2 \pm 13.2$ & Normal \\
\hline \multirow[t]{3}{*}{ Present study } & 50 & $31.14 \pm 9.62$ & $41.36 \pm 9.11$ & Normal \\
\hline & 29 & & $43.72 \pm 9.32$ & Normal males \\
\hline & 21 & & $38.10 \pm 7.91$ & Normal females \\
\hline Study & $N$ & Age (years) & $\mathrm{PI}\left({ }^{\circ}\right)$ & Description \\
\hline Duval-Beaupere et al. (1992) [7] & 17 & $29.4 \pm 11.0$ & $51.8 \pm 9.4$ & Normal \\
\hline \multirow[t]{2}{*}{ Rajnics et al. (2001) [8] } & 15 & $33.5 \pm 2.9$ & $53.6 \pm 8.9$ & Normal males \\
\hline & 15 & $35.1 \pm 3.0$ & $55.1 \pm 8.4$ & Normal females \\
\hline \multirow[t]{3}{*}{ Vialle et al. (2005) [1] } & 300 & $35.4 \pm 12.0$ & $54.7 \pm 10.6$ & Normal \\
\hline & 190 & & $53.0 \pm 10.6$ & Normal males \\
\hline & 110 & & $56.0 \pm 10.0$ & Normal females \\
\hline Roussouly et al. (2005) [12] & 160 & 27 & $51.9 \pm 10.7$ & Normal \\
\hline Boulay et al. (2006) [13] & 149 & $30.8 \pm 6.0$ & $53.1 \pm 9.0$ & Normal \\
\hline Legaye (2007) [14] & 145 & $40.7 \pm 18.7$ & $50.2 \pm 10.6$ & Normal \\
\hline \multirow[t]{2}{*}{ Janssen et al. (2009) [15] } & 30 & 27 & $53 \pm 10$ & Normal males \\
\hline & 30 & 26 & $50 \pm 10$ & Normal females \\
\hline \multirow[t]{2}{*}{ Mac-Thiong et al. (2010) [16] } & 354 & $37.9 \pm 14.7$ & $52.7 \pm 10.0$ & Normal males \\
\hline & 355 & $37.7 \pm 13.9$ & $52.4 \pm 10.8$ & Normal females \\
\hline \multirow[t]{3}{*}{ Lee et al. (2011) [2] } & 86 & 28.19 & $47.8 \pm 9.3$ & Normal \\
\hline & 54 & & $48.8 \pm 7.3$ & Normal males \\
\hline & 32 & & $46.1 \pm 9.5$ & Normal females \\
\hline \multirow[t]{3}{*}{ Pratali et al. (2014) [3] } & 50 & 34.85 & $48.7 \pm 9.6$ & Normal \\
\hline & 25 & 32.3 & $49.1 \pm 6.4$ & Normal males \\
\hline & 25 & 37.4 & $48.3 \pm 9.6$ & Normal females \\
\hline \multirow[t]{3}{*}{ Present study } & 50 & $31.14 \pm 9.62$ & $48.52 \pm 8.99$ & Normal \\
\hline & 29 & & $46.31 \pm 9.28$ & Normal males \\
\hline & 21 & & $51.57 \pm 7.79$ & Normal females \\
\hline Study & $N$ & Age (years) & $\operatorname{PRS} 1\left(^{\circ}\right)$ & Description \\
\hline Jackson et al. (1998) [5] & 50 & $39.4 \pm 9.5$ & $31.2 \pm 7.9$ & Normal \\
\hline Jackson et al. (2000) [18] & 20 & 46 & $31 \pm 8.7$ & Normal \\
\hline Jackson et al. (2003) [6] & 75 & 39 & $30.9 \pm 9.8$ & Normal \\
\hline Legaye (2007) [14] & 145 & $40.7 \pm 18.7$ & $35.2 \pm 9.6$ & Normal \\
\hline \multirow[t]{3}{*}{ Present study } & 50 & $31.14 \pm 9.62$ & $37.02 \pm 8.05$ & Normal \\
\hline & 29 & & $38.93 \pm 8.61$ & Normal males \\
\hline & 21 & & $34.38 \pm 6.50$ & Normal females \\
\hline Study & $N$ & Age (years) & $\mathrm{PT}\left({ }^{\circ}\right)$ & Description \\
\hline \multirow[t]{2}{*}{ Legaye et al. (1998) [19] } & 28 & $24 \pm 5.8$ & $11.9 \pm 6.6$ & Normal males \\
\hline & 21 & & $10.3 \pm 4.8$ & Normal females \\
\hline Roussouly et al. (2005) [12] & 160 & 27 & $11.99 \pm 6.46$ & Normal \\
\hline
\end{tabular}


Table 6. (continued)

\begin{tabular}{|c|c|c|c|c|}
\hline Study & $N$ & Age (years) & PT $\left(^{\circ}\right)$ & Description \\
\hline \multirow[t]{3}{*}{ Vialle et al. (2005) [1] } & 300 & $35.4 \pm 12.0$ & $13.2 \pm 6$ & Normal \\
\hline & 190 & & $13 \pm 6$ & Normal males \\
\hline & 110 & & $13.6 \pm 6$ & Normal females \\
\hline Boulay et al. (2006) [13] & 149 & $30.8 \pm 6.0$ & $11.96 \pm 6.44$ & Normal \\
\hline \multirow[t]{2}{*}{ Janssen et al. (2009) [15] } & 30 & 27 & $12 \pm 5.7$ & Normal males \\
\hline & 30 & 26 & $11 \pm 6.8$ & Normal females \\
\hline \multirow[t]{2}{*}{ Mac-Thiong et al. (2010) [16] } & 354 & $37.9 \pm 14.7$ & $13.4 \pm 6.7$ & Normal males \\
\hline & 355 & $37.7 \pm 13.9$ & $12.7 \pm 7.0$ & Normal females \\
\hline \multirow[t]{3}{*}{ Lee et al. (2011) [2] } & 86 & 28.19 & $11.5 \pm 5.3$ & Normal \\
\hline & 54 & & $11.4 \pm 5.4$ & Normal males \\
\hline & 32 & & $11.6 \pm 5.1$ & Normal females \\
\hline \multirow[t]{3}{*}{ Pratali et al. (2014) [3] } & 50 & 34.85 & $12.15 \pm 6.2$ & Normal \\
\hline & 25 & 32.3 & $12.1 \pm 6.2$ & Normal males \\
\hline & 25 & 37.4 & $12.2 \pm 5.3$ & Normal females \\
\hline \multirow[t]{3}{*}{ Present study } & 50 & $31.14 \pm 9.62$ & $9.30 \pm 7.16$ & Normal \\
\hline & 29 & & $9.17 \pm 8.40$ & Normal males \\
\hline & 21 & & $9.47 \pm 5.19$ & Normal females \\
\hline Study & $N$ & Age (years) & SHA $\left(^{\circ}\right)$ & Description \\
\hline \multirow{2}{*}{ Legaye et al. (1998) [19] } & 28 & $24 \pm 5.8$ & $41.9 \pm 8.7$ & Normal males \\
\hline & 21 & & $38.2 \pm 7.8$ & Normal females \\
\hline Roussouly et al. (2005) [12] & 160 & 27 & $39.9 \pm 8.2$ & Normal \\
\hline \multirow[t]{3}{*}{ Vialle et al. (2005) [1] } & 300 & $35.4 \pm 12.0$ & $41.2 \pm 8.5$ & Normal \\
\hline & 190 & & $41 \pm 8.5$ & Normal males \\
\hline & 110 & & $43.2 \pm 8.4$ & Normal females \\
\hline Boulay et al. (2006) [13] & 149 & $30.8 \pm 6.0$ & $41.18 \pm 6.96$ & Normal \\
\hline \multirow[t]{2}{*}{ Janssen et al. (2009) [15] } & 30 & 27 & $41 \pm 8.6$ & Normal males \\
\hline & 30 & 26 & $39 \pm 7.6$ & Normal females \\
\hline \multirow[t]{2}{*}{ Mac-Thiong et al. (2010) [16] } & 354 & $37.9 \pm 14.7$ & $39.3 \pm 8.0$ & Normal males \\
\hline & 355 & $37.7 \pm 13.9$ & $39.8 \pm 7.9$ & Normal females \\
\hline \multirow[t]{3}{*}{ Lee et al. (2011) [2] } & 86 & 28.19 & $36.3 \pm 7.8$ & Normal \\
\hline & 54 & & $37.3 \pm 7.1$ & Normal males \\
\hline & 32 & & $34.4 \pm 8.6$ & Normal females \\
\hline \multirow[t]{3}{*}{ Pratali et al. (2014) [3] } & 50 & 34.85 & $38 \pm 8.4$ & Normal \\
\hline & 25 & 32.3 & $38.2 \pm 6.9$ & Normal males \\
\hline & 25 & 37.4 & $37.8 \pm 8.4$ & Normal females \\
\hline \multirow[t]{3}{*}{ Present study } & 50 & $31.14 \pm 9.62$ & $39.14 \pm 7.05$ & Normal \\
\hline & 29 & & $37.0 \pm 6.26$ & Normal males \\
\hline & 21 & & $42.10 \pm 7.16$ & Normal females \\
\hline Study & $N$ & Age (years) & $\mathrm{PO}(\mathrm{mm})$ & Description \\
\hline \multirow[t]{2}{*}{ Legaye et al. (1998) [19] } & 28 & $24 \pm 5.8$ & $22.6 \pm 12.5$ & Normal males \\
\hline & 21 & & $19.2 \pm 7.9$ & Normal females \\
\hline \multirow[t]{3}{*}{ Present study } & 50 & $31.14 \pm 9.62$ & $18.22 \pm 12.78$ & Normal \\
\hline & 29 & & $17.83 \pm 14.85$ & Normal males \\
\hline & 21 & & $18.76 \pm 9.55$ & Normal females \\
\hline Study & $N$ & Age (years) & LLA $\left(^{\circ}\right)$ & Description \\
\hline \multirow[t]{2}{*}{ Legaye et al. (1998) [19] } & 28 & $24 \pm 5.8$ & $61.4 \pm 10.2$ & Normal males \\
\hline & 21 & & $58.1 \pm 10.8$ & Normal females \\
\hline Boulay et al. (2006) [13] & 149 & $30.8 \pm 6.0$ & $66.36 \pm 9.47$ & Normal \\
\hline \multirow[t]{3}{*}{ Present study } & 50 & $31.14 \pm 9.62$ & $58.78 \pm 9.51$ & Normal \\
\hline & 29 & & $56.21 \pm 9.54$ & Normal males \\
\hline & 21 & & $62.33 \pm 8.46$ & Normal females \\
\hline Study & $N$ & Age (years) & SLA L1-L3 $\left(^{\circ}\right)$ & Description \\
\hline \multirow[t]{3}{*}{ Present study } & 50 & $31.14 \pm 9.62$ & $17.54 \pm 3.81$ & Normal \\
\hline & 29 & & $17.0 \pm 4.01$ & Normal males \\
\hline & 21 & & $18.28 \pm 3.46$ & Normal females \\
\hline
\end{tabular}


Table 6. (continued)

\begin{tabular}{|c|c|c|c|c|}
\hline Study & $N$ & Age (years) & SLA L3-S1 $\left(^{\circ}\right)$ & Description \\
\hline Present study & $\begin{array}{l}50 \\
29 \\
21\end{array}$ & $31.14 \pm 9.62$ & $\begin{array}{l}43.46 \pm 8.15 \\
41.48 \pm 6.40 \\
46.19 \pm 9.59\end{array}$ & $\begin{array}{l}\text { Normal } \\
\text { Normal males } \\
\text { Normal females }\end{array}$ \\
\hline Study & $N$ & Age (years) & $\operatorname{LSA}\left({ }^{\circ}\right)$ & Description \\
\hline Present study & $\begin{array}{l}50 \\
29 \\
21\end{array}$ & $31.14 \pm 9.62$ & $\begin{array}{c}10.56 \pm 3.58 \\
9.37 \pm 1.98 \\
12.1 \pm 4.58\end{array}$ & $\begin{array}{l}\text { Normal } \\
\text { Normal males } \\
\text { Normal females }\end{array}$ \\
\hline Study & $N$ & Age (years) & SIA $\left(^{\circ}\right)$ & Description \\
\hline Present study & $\begin{array}{l}50 \\
29 \\
21\end{array}$ & $31.14 \pm 9.62$ & $\begin{array}{l}48.62 \pm 6.62 \\
46.72 \pm 4.97 \\
51.23 \pm 7.78\end{array}$ & $\begin{array}{l}\text { Normal } \\
\text { Normal males } \\
\text { Normal females }\end{array}$ \\
\hline Study & $N$ & Age (years) & $\operatorname{LTA}\left(^{\circ}\right)$ & Description \\
\hline $\begin{array}{l}\text { Roussouly et al. (2005) [12] } \\
\text { Present study }\end{array}$ & $\begin{array}{c}160 \\
50 \\
29 \\
21\end{array}$ & $\begin{array}{c}27 \\
31.14 \pm 9.62\end{array}$ & $\begin{array}{l}-5.71 \pm 4.59 \\
-2.48 \pm 4.98 \\
-.2 .96 \pm 4.64 \\
-1.80 \pm 5.45\end{array}$ & $\begin{array}{l}\text { Normal } \\
\text { Normal } \\
\text { Normal males } \\
\text { Normal females }\end{array}$ \\
\hline
\end{tabular}

the importance of studies in this format, aimed at adjusting the radiographic parameters for different populations [1-3]. Furthermore, the normative values derived from the present data can be utilized clinically to evaluate spinal deformities and in deformity corrective measures (surgical/conservative) targeting to achieve normal spino-pelvic balance in the Indian population.

\section{Conclusion}

This study presents the various spino-pelvic radiographic parameter values of a sample of the normal asymptomatic Indian population. There was significant difference in radiographic parameters between males and females in about half of the parameters studied in the sample. The values obtained are comparable with the values presented as normal in the literature. A comparison of the study results with data published about other populations revealed no differences in any of the pelvic parameters between the Indian, Brazilian, and Korean populations. There were differences in pelvic incidence between the Indian and European populations both in the total sample and in the male and female groups. There were differences in sacral slope between the Indian and European populations in relation to the total sample and the female group. More extensive studies are needed to further validate the findings of the present study.

\section{Conflict of interest}

The authors declare no conflict of interest.

\section{References}

1. Vialle R, Levassor N, Rillardon L (2005) Radiographic analysis of the sagittal alignment and balance of the spine in asymptomatic subjects. J Bone Joint Surg Am 87, 260-267.
2. Lee CS, Chung SS, Kang KC, Park SJ, Shin SK (2011) Normal patterns of sagittal alignment of the spine in young adults radiological analysis in a Korean population. Spine 36, E1648-E1654.

3. Pratali RR, Luz CO, Barsotti CG, Santos FE, Oliveira CS (2014) Analysis of sagittal balance and spinopelvic parameters in a Brazilian population sample. Coluna/Columna 13, $108-111$.

4. Vrtovec T, Janssen M, Likar B, et al. (2012) A review of methods for evaluating the quantitative parameters of sagittal pelvic alignment. Spine J 12, 433-446.

5. Jackson R, Peterson M, McManus A, Hales C (1998) Compensatory spino-pelvic balance over the hip axis and better reliability in measuring lordosis to the pelvic radius on standing lateral radiographs of adult volunteers and patients. Spine 23, 1750-1767.

6. Jackson R, Phipps T, Hales C, Surber J (2003) Pelvic lordosis and alignment in spondylolisthesis. Spine 28, 151-160.

7. Duval-Beaupere G, Schmidt C, Cosson P (1992) A barycentremetric study of the sagittal shape of spine and pelvis: the conditions required for an economic standing position. Ann Biomed Eng 20, 451-462.

8. Rajnics P, Pomero V, Templier A (2001) Computer-assisted assessment of spinal sagittal plane radiographs. J Spinal Disord Tech 14, 135-142.

9. During J, Goudfrooij H, Keessen W (1985) Toward standards for posture: postural characteristics of the lower back system in normal and pathologic conditions. Spine 10, 83-87.

10. Itio E (1991) Roentgenographic analysis of posture in spinal osteoporotics. Spine 16, 750-756.

11. Kim WJ, Kang JW, Yeom JS, et al. (2003) A comparative analysis of sagittal spinal balance in 100 asymptomatic young and older aged volunteers. J Korean Soc Spine Surg 10, $327-334$

12. Roussouly P, Gollogly S, Berthonnaud E, Dimnet J (2005) Classification of the normal variation in the sagittal alignment of the human lumbar spine and pelvis in the standing position. Spine 30, 346-353. 
13. Boulay C, Tardieu C, Hecquet J (2006) Sagittal alignment of spine and pelvis regulated by pelvic incidence: standard values and prediction of lordosis. Eur Spine J 15, 415-422.

14. Legaye J (2007) The femoro-sacral posterior angle: an anatomic sagittal pelvic parameter usable with dome-shaped sacrum. Eur Spine J 16, 219-225.

15. Janssen M, Drevelle X, Humbert L, et al. (2009) Differences in male and female spino-pelvic alignment in asymptomatic young adults: a three-dimensional analysis using upright lowdose digital biplanar X-rays. Spine 34, 826-832.

16. Mac-Thiong JM, Roussouly P, Berthonnaud E, Guigui P (2010) Sagittal parameters of global spinal balance: normative values from a prospective cohort of seven hundred nine Caucasian asymptomatic adults. Spine 35, 1193-1198.

17. Gangnet N, Dumas R, Pomero V, et al. (2006) Threedimensional spinal and pelvic alignment in an asymptomatic population. Spine 31, E507-12.

18. Jackson R, Kanemura T, Kawakami N, Hales C (2000) Lumbopelvic lordosis and pelvic balance on repeated standing lateral radiographs of adult volunteers and untreated patients with constant low back pain. Spine 25, 575-586.

19. Legaye J, Duval-Beaupere G, Hecquet J, Marty C (1998) Pelvic incidence: a fundamental pelvic parameter for three-dimensional regulation of spinal sagittal curves. Eur Spine J 7, 99-103.

Cite this article as: Singh R, Yadav SK, Sood S, Yadav RK \& Rohilla R (2018) Spino-pelvic radiological parameters in normal Indian population. SICOT-J, 4, 14 